\title{
THE FUTURE OF PERSONALIZED MEDICINE: ONE STEP MELANOMA SURGERY
}

\author{
G. Tchernev, G. Poterov, V. Malev \\ Clinic for Dermatology, Venereology and Dermatologic Surgery "Onkoderma" - Sofia, Bulgaria
}

\begin{abstract}
The divergent, personalized approach in the surgical treatment of cutaneous melanoma is the one in which the treatment of the neoplasm differs from that proposed within the generally accepted standards or guidelines. According to their presumption, guidelines are not obligatory for the treatment of a certain type of disease and cannot replace the judgment of the clinician. Which to a large extent determines the freedom (or possible one) of the clinician's action regarding the „personalization" in the choice of a new, divergent therapy. It is interesting, for example, that the occurrence of locoregional recurrences in patients with melanoma after guideline therapy insures clinicians against both criticism of treatment choice and the end results. However, the lack of recurrences after innovative/personalized surgical treatment of cutaneous melanoma is accompanied for unknown reasons by a serious dose of unwarranted criticism. The fact is that a personalized surgical approach in the treatment of skin melanomas and the recommended by AJCC guidelines approach lead to exactly the same end results and that should not be ignored. The difference lies in the fact that this end result can be achieved by one step melanoma surgery (OSMS), for example, which is carried out in a single surgical session. Several advantages of OSMS can be noted: 1) it provides high efficiency in a short time, even in the initial stage of the disease, 2) it is cost-effective, and 3) according to initial clinical observations we have a much lower to no propensity for locoregional relapses.
\end{abstract}

Key words: skin melanoma, AJCC, OSMS, tumor thickness, surgical approach

Corresponding author: Prof. Georgi Tchernev, Clinic for Dermatology, Venereology and Dermatologic Surgery "Onkoderma", 26 General Skobelev blvd., 1606 Sofia, e-mail: georgi_tchernev@yahoo.de, GSM: 0359885588424

\section{INTRODUCTION}

$\mathrm{M}$ elanoma is a malignant tumor most commonly affecting the skin, the incidence of which is increasing worldwide [1]. Although in most cases tumors are detected at an early stage of their development, mortality in patients with cutaneous melanoma remains relatively stable [2]. This requires a rethinking of the current therapeutic strategy in order to reduce relapses after therapy and patient mor- tality in general. Surgery remains the main method in the early treatment of primary melanoma [3]. Surgical treatment of melanoma refers to certain rules, which include primary excision of melanoma with a surgical safety margin of $0.5 \mathrm{~cm}$ in all directions, subsequent histological examination of the removed lesion and determination of Breslow tumor thickness [4]. Based on the already stated tumor thickness, the need for repeated surgical excision is determined, which is accompanied by or without removal of the so-called 
draining lymph node [4]. The innovative approach in the treatment of cutaneous melanoma aims to reduce the number of surgical sessions and to minimize the subsequent mental trauma for the patients themselves [5, 6]. Another important aspect that is observed is the economic parameters or the financial point of view, which for about 300,000 melanoma patients per year could be of colossal proportions [7]. We present 2 cases of patients with melanocytic lesions, discussing the applicability of the standard and customized, divergent surgical approach depending on: 1) the clinical morphology of the primary lesion, 2 ) the dermatoscopic finding and 3) the presence or absence of specific ultrasound equipment for preoperative measurement of tumor thickness.

\section{CASE REPORT 1}

We present a 47-year-old patient with a lesion in the area of the head about 6 months old (Figs. 1a, 1b, 1c), discovered accidentally after a visit to a hairdresser and its subsequent mechanical irritation and bleeding, two or three weeks before entering the hospital. The patient denied taking medication, as well as the presence of concomitant diseases. The patient was admitted to the clinic in order to determine the subsequent diagnostic and therapeutic approach. During the dermatological examination we observed a solitary, blue-colored, tumor formation measuring 5 by $5 \mathrm{~mm}$ in the scalp area (Figs. 1a, 1b, 1c). In the differential-diagnostic aspect, Blue nevus, nodular melanoma, nodular melanoma based on blue nevus, melanoma metastasis, glomangioma or angiokeratoma were considered.

Surgical removal of the tumor formation was performed under local anesthesia with a surgical safety field of $0.5 \mathrm{~cm}$ according to AJCC (Figs. 1d, 1e, 1f), and the resulting surgical defect was closed by single, interrupted sutures. Histopathological verification showed evidence of a Blue nevus. Immunohistochemical examination showed the following expression: S-100; Melan A; HMB-45: positive reaction. Postoperative treatment included active monitoring.
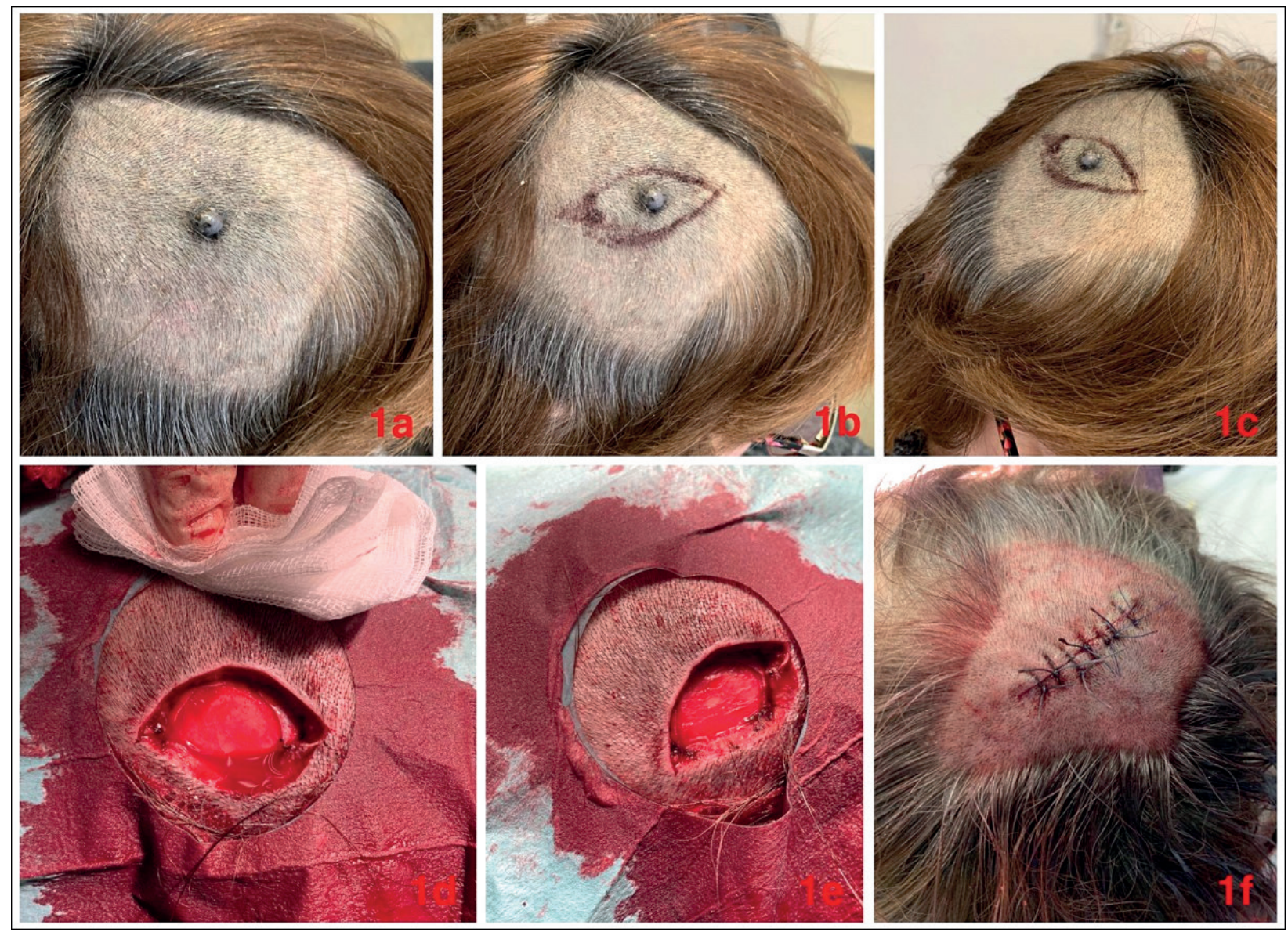

Fig. 1. a, b, c: show solitary, blue-colored, tumor formation measuring 5 by $5 \mathrm{~mm}$ in the scalp area

d, e show: Intraoperative view: elliptical excision of the Blue nevus, located in the scalp area

f shows: The closure of surgical defect by single, discontinuous sutures 

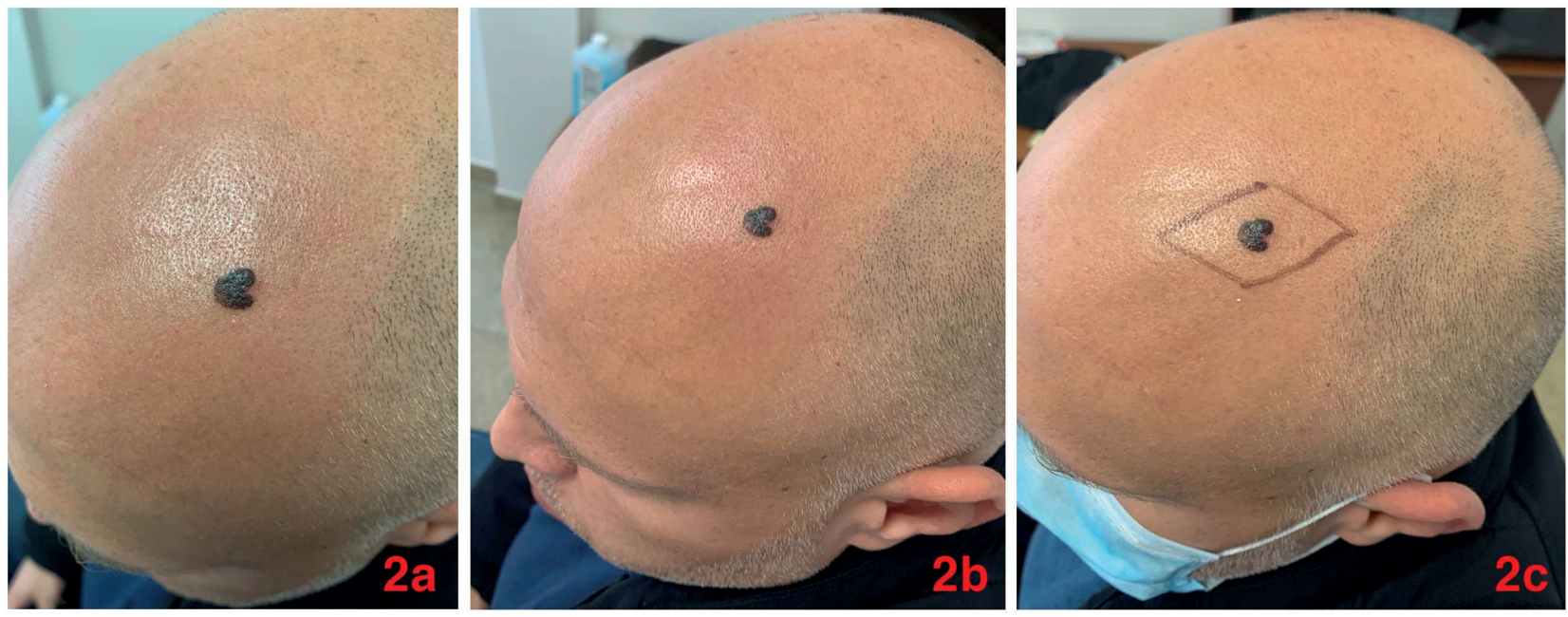

Figs. $\mathbf{2}$ a, $\mathbf{2}$ b, $\mathbf{2}$ c show: a slightly raised, dark brown pigmented lesion with a well-defined but irregular edge located in the scalp area

\section{CASE REPORT 2}

A 45-year-old man with a lesion on the scalp, dating from about 6 years, which had grown rapidly over
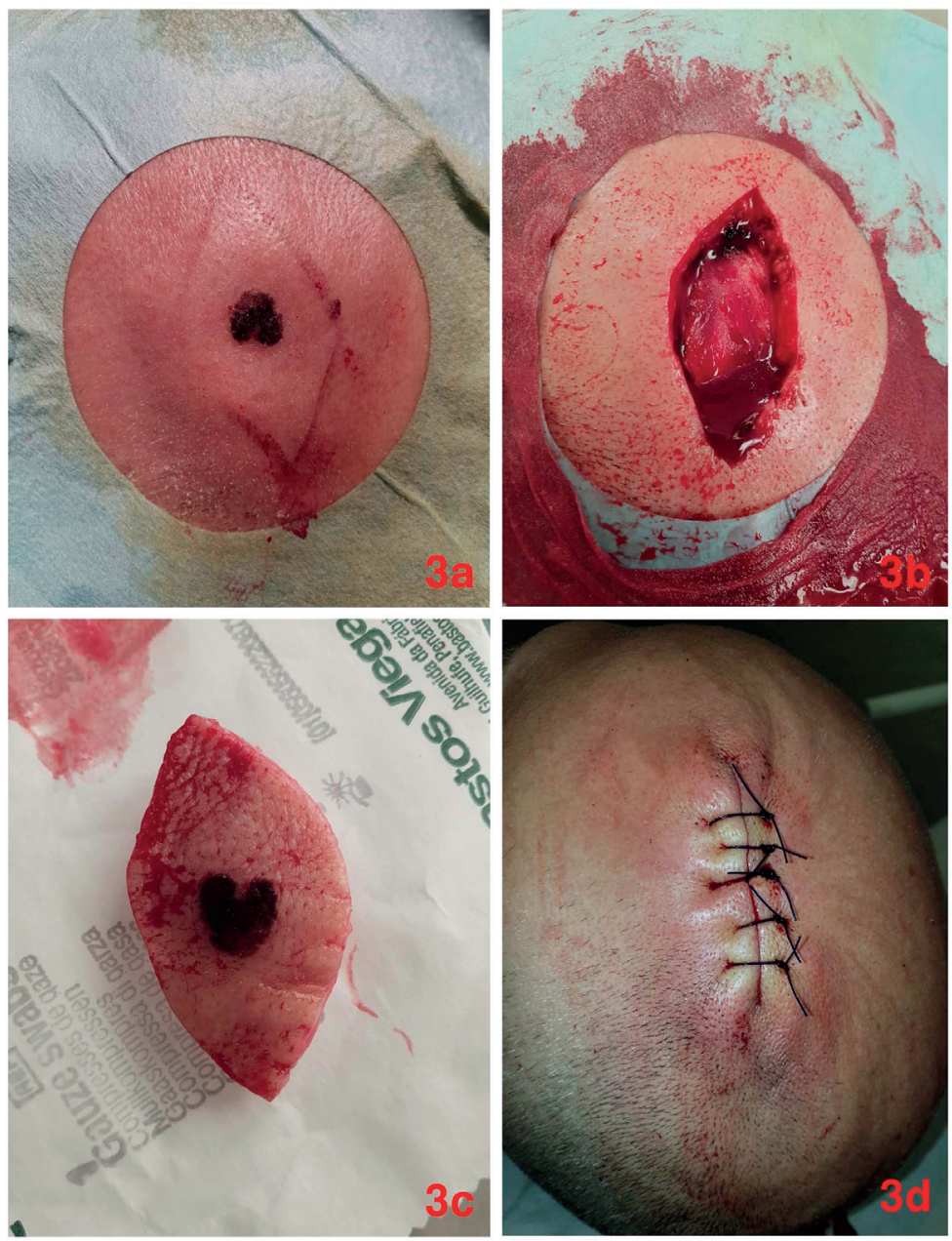

Fig. 3 a shows: Preoperative measurement of the surgical security field, according to the guideline for one-step melanoma surgery; b, c show: Intraoperative view: elliptical excision of the melanoma, located in the scalp area; $\mathbf{d}$ shows: The closure of surgical defect by single, discontinuous sutures the last nine months, changed its color, and became itching (Figs. 2a, 2b, 2c). From the anamnesis, the patient did not report concomitant diseases and medication. There was evidence of painful sunburns on the body and face in the past. During the dermatological examination we observed a slightly raised, dark-brown pigmented lesion with a well-defined but irregular edge located in the scalp area (Figs. 2a, 2b, $2 c)$. From the collected anamnestic and available clinical data, we concluded that it is probably malignant melanoma. Laboratory tests were performed that showed no deviations from normal paraclinical values, with the exception of creatinine level - $119 \mu \mathrm{mol}$ (ref. range up to $110 \mu \mathrm{mol}$ ). No metastases were found from the CT of the neck/head, single lymph nodes up to $8 \mathrm{~mm}$ in size in the middle and upper cervical third (insignificant) were visualized bilaterally along the vascular-nervous bundle. Ultrasound diagnosis and radiography of the lungs and abdomen showed no pathological changes. Surgical removal of the tumor formation was performed under local anesthesia with a surgical field of $1 \mathrm{~cm}$ (Figs. 3a, 3b, 3c), and subsequently the surgical defect was closed by single, interrupted sutures (Fig. 4). The histopathological examination revealed the diagnosis superficial spreading melanoma (SSM), T1bNOM0, stage IA, Clark II, with a Breslow thickness of $1 \mathrm{~mm}$, without ulceration and spontaneous regeneration, with low mitotic activity and well-defined lymphocytic stromal reaction, without perineural invasion and clean resection fields. 


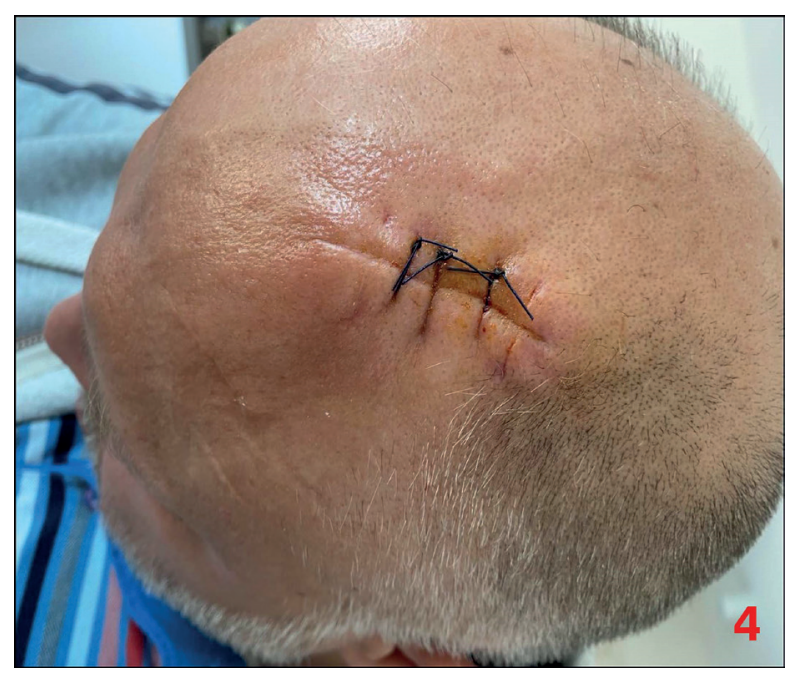

Fig. 4. The removal of surgical sutures and the perfect postoperative cicatrix

\section{DISCUSSION}

Malignant melanoma is a disease, the diagnosis and treatment of which put clinicians to a serious test of the mind and raise the question of whether they tend to be flexible and innovative [3].

The current guidelines for the treatment of primary cutaneous melanoma in situ (MIS) according to AJCC (Table 1), based on Breslow thickness, include resection of 0.5 to $1 \mathrm{~cm}$ for in situ melanoma; a 1.0 $\mathrm{cm}$ operative field is also the recommended resection area for melanoma up to $1.0 \mathrm{~mm}$ and between 1 and $2 \mathrm{~mm}$ [4]. According to the recommendations (Table 1 ), this area is $1 \mathrm{~cm}$ for melanomas with a thickness between 1.01-2.00 mm; two centimeters is also the recommended area for the treatment of melanomas with a thickness of 2.01-4 mm [4]. In melanomas thicker than $4 \mathrm{~mm}$, resection of more than $2 \mathrm{~cm}$ in all directions is not recommended [4]. If we follow the current recommendations of the AJCC, the treatment of melanoma should begin with resection with a margin of operative safety of $0.5 \mathrm{~cm}$ in all directions, followed by postoperative measurement of tumor thickness and mandatory planning of re-excision as soon as possible [4]. Tumor thickness in cutaneous melanomas is in fact the main indicator determining the plan of action, the choice of surgical boundaries, re-excision, additional determination of a draining lymph node and possible lymph dissection $[8,9]$. One step melanoma surgery offers a new innovative approach, which is undoubtedly one of the innovations in medicine of our time [10,11]. The innovation is applicable to almost all patients with clear clinical and dermatoscopic criteria for dysplastic nevi, thin cutaneous melanomas or melanoma in situ lesions, even without the need for preoperative ultrasound measurement of tumor thickness [12]. It is believed that preoperative ultrasound diagnostics with a good resolution of $20 \mathrm{MHz}$ to a very large extent correctly identifies thin melanomas and this allows to choose the most appropriate surgical boundaries and possibly to save the need for further re-excision [13]. The recommendations for OSMS (Table 2) state that in all lesions that are clinically and dermatoscopically indicative of cutaneous melanoma or in situ melanoma, preoperative ultrasound may not be mandatory [12].

Table 1. AJCC recommendations for surgical margins: always two surgical sessions

\begin{tabular}{|l|l|}
\hline Breslow thickness & Recommended surgical margins \\
\hline Melanoma in situ & $\begin{array}{l}0.5 \mathrm{~cm} \text { (primary excision with } 0,5 \mathrm{~cm} \\
\text { in all directions, followed by secondary } \\
\text { excision } 0.2 / 0.5 \mathrm{~cm} \text { additionally) }\end{array}$ \\
\hline$<1 \mathrm{~mm}$ & $\begin{array}{l}0.5 \mathrm{~cm} \text { primary excision (followed by } \\
\text { secondary excision with 0,5 cm in all } \\
\text { directions) }\end{array}$ \\
\hline $1.00 \mathrm{~mm}$ & $\begin{array}{l}0.5 \mathrm{~cm} \text { primary excision (followed by sec- } \\
\text { ondary excision with 0,5 cm with SLND) }\end{array}$ \\
\hline $2-4 \mathrm{~mm}$ & $\begin{array}{l}0.5 \mathrm{~cm} \text { primary excision (followed by } \\
\text { secondary excision with 1,5 cm in all } \\
\text { directions/with SLND) }\end{array}$ \\
\hline$>4 \mathrm{~mm}$ & $\begin{array}{l}0.5 \mathrm{~cm} \text { primary excision (followed by } \\
\text { secondary excision with 1,5 cm in all direc- } \\
\text { tions/ without SLND if nodes not enlarged) }\end{array}$ \\
\hline
\end{tabular}

If the primary lesion has a tumor thickness of more than $1 \mathrm{~mm}$ and less than $2 \mathrm{~mm}$, the operative field should be $1 \mathrm{~cm}$ combined with the simultaneous removal of the draining lymph node within one surgical session (Table 2) [5, 14]. In melanomas between 2 and $4 \mathrm{~mm}$ thickness, ultrasound can be used again, with the surgical safety field being $2 \mathrm{~cm}$ in all directions and the draining lymph node being removed in parallel (Table 2) [5, 14]. For tumor thicknesses greater than $4 \mathrm{~mm}$, OSMS again offers adequate treatment within one surgical session (Table 2) [6]. When the locoregional lymph nodes are affected, the primary lesion is removed within one surgical session together with them, observing a field of operative safety of $2 \mathrm{~cm}$ in all directions (Table 2). If the lymph nodes are not clinically and ultrasound affected, it is not recommended to determine a draining lymph node (even in tumors over $4 \mathrm{~mm}$ thick) due to the likely presence of metastases $[3,5,10]$.

Thus described, the innovative „One-step melanoma surgery" method leads to a reduction in the number of surgical interventions from two to one, as well as to: the absolute lack of the possibility of violating the deadlines within which the secondary excision should be performed $[3,5]$. 
Table 2. Personalized melanoma surgery \& One step melanoma surgery (OSMS) recommendations for new surgical margins - one surgical session

\begin{tabular}{|l|l|}
\hline Breslow thickness & Recommended surgical margins \\
\hline Melanoma in situ & $\mathrm{cm}$ (clinical/dermatoscopical evaluation obligate/if possibility for echographical examination - from benefit) \\
\hline$<1 \mathrm{~mm}$ & $\begin{array}{l}\mathrm{cm} \text { (clinical/dermatoscopical evaluation obligate/if possibility for echographical examination - from benefit if } \\
\text { available!) }\end{array}$ \\
\hline $1.01-2.0 \mathrm{~mm}$ & $\begin{array}{l}1.0 \mathrm{~cm} \text { (clinical/dermatoscopical evaluation obligate) (with SLND), (echographical tumour thickness mea- } \\
\text { surement preoperatively) }\end{array}$ \\
\hline $2-4 \mathrm{~mm}$ & $\begin{array}{l}2 \mathrm{~cm} \text { (clinical/dermatoscopical evaluation obligate) (with SLND) echographical tumour thickness measure- } \\
\text { ment Preoperatively }\end{array}$ \\
\hline$>4 \mathrm{~mm}$ & $\begin{array}{l}2.0 \mathrm{~cm} \text { (clinical/dermatoscopical evaluation obligate) } \\
\text { a) no enlarged lymph nodes }-2 \mathrm{~cm} \text { resection is sufficient! } \\
\text { b) in the presence of enlarged lymph nodes - to be removed together with the reexcison of the primary } \\
\text { tumourous tissue! } \\
\text { c) If lymphatic nodes involutive/benign (after AB therapy): no resection! }\end{array}$ \\
\hline
\end{tabular}

When there is ambiguity regarding a certain type of melanocyte lesions and the possibility that this type of lesion may be nodular melanoma (such as patient 1 described by us) with a thickness of more than 1 $\mathrm{mm}$, the applicability of OSMS is questionable and it is desirable to perform surgical treatment by AJCC rules.

The reason is that in lesions with incompletely clear clinical and dermatoscopic criteria for nodular melanoma/metastasis or irritated blue nevus, for example, even if the predicted/measured tumor thickness is more than $1 \mathrm{~mm}$, AJCC guidelines line with/ or give significantly more a high dose of certainty for the clinician regarding: 1) the possible danger of a more aggressive (in this case illogical) excision with a wider field of surgical safety of 1 or more centimeters, and 2) of a possible excision described in point 1 in combination with the additional conduction of a sentinel lymph node (again unreasonably aggressive therapy). Both mentioned variants turn out to be illogically determined not only from a professional, but also from a legal point of view, and the reason for this is: the lack of certainty regarding the dignity of the primary tumor lesion due to its difficult to interpret (clinical and dermatoscopic) morphology.

In the described second patient, the lesion was identified clinically and dermatoscopically as a thin melanoma with a possible tumor thickness of less than 1 $\mathrm{mm}$ and was approached individually, with a different from the AJCC surgical field, namely a total resection field of $1 \mathrm{~cm}$ in all directions, but within only one surgical session. This saves secondary surgical excision, which is recommended by the AJCC, but the total resection field is the same for both the AJCC and the OSMS recommendations $[3,5]$.
Clinical morphology and dermatoscopic findings are often the key in the selection of the field of surgical safety and the corresponding guidelines $-\mathrm{AJCC} /$ OSMS [3, 5]. Preoperative ultrasound measurement of tumor thickness is not always mandatory and necessary when the lesion is indicative of thin melanoma, dysplastic nevus, or melanoma in situ [12]. The individual or personalized surgical approach in patients with melanoma should take into account not only the AJCC guidelines, but also those of the OSMS namely, personalized surgical treatment [15]. The reduction in the number of surgical sessions within the new shared surgical treatment algorithms is probably also the reason for the reduced to completely absent tendency to locoregional recurrences in patients with cutaneous melanoma $[3,5,12]$.

Another problem that somewhat determines the need for a more liberal model and at the same time a more aggressive model for surgical treatment of melanoma is the lack of a logical requirement for full compliance of clinically measured boundaries for surgical resection with histopathologically evaluated distances of resection edges from the tumor tissue in the histopathological preparations according to the AJCC recommendations [15].

Disclosure summary: The authors have nothing to disclose.

\section{REFERENCES}

1. Tchernev G, Orfanos CE. Downregulation of cell cycle modulators p21, p27, p53, Rb and proapoptotic Bcl-2-related proteins Bax and Bak in cutaneous melanoma is associated with worse patient prognosis: preliminary findings. J Cutan Pathol. 2007;34(3):247-256. doi:10.1111/j.1600-0560.2006.00700.x 
2. Matthews NH, Li WQ, Qureshi AA, et al. Epidemiology of Melanoma. In: Ward WH, Farma JM, editors. Cutaneous Melanoma: Etiology and Therapy [Internet]. Brisbane (AU): Codon Publications; 2017 Dec 21. Chapter 1. Available from: https:// www.ncbi.nlm.nih.gov/books/NBK481862/ doi:10.15586/codon.cutaneousmelanoma.2017.ch1

3. Tchernev G, Temelkova I. The Novel Surgical Margin for One Step Melanoma Surgery (OSMS) (Without Using Ultrasonography Preoperatively): The End of Conformity! „Vivere militare est!“ Open Access Maced J Med Sci. 2018;6(7):1263-1266. Published 2018 Jul 12. doi:10.3889/oamjms.2018.288

4. Bichakjian K, Halpern C, Johnson M et al. Guidelines of care for the management of primary cutaneous melanoma. American Academy of Dermatology. J Am Acad Dermatol. 2011;65(5):1032-47.

5. Tchernev G, Chernin S, Lozev I et al. Innovative One Step Melanoma Surgical Approach (OSMS): Not a Myth-It's a Reality!Case Related Analysis of a Patient with a Perfect Clinical Outcome Reported from the Bulgarian Society for Dermatologic Surgery (BULSDS)! Open Access Maced J Med Sci. 2018; 6(4):673-674

6. Tchernev G. One Step Melanoma Surgery for Patient with Thick Primary Melanomas: "To Break the Rules, You Must First Master Them!" Open Access Maced J Med Sci. 2018;6(2):367-371.

7. Tchernev G, Temelkova I. Annually over 9 billion dollars less for one-step melanoma surgery: sounds good?. J Biol Regul Homeost Agents. 2019;33(5):1493-1496.

8. Joyce D, Skitzki JJ. Surgical Management of Primary Cutaneous Melanoma. Surg Clin North Am. 2020;100(1):61-70. doi:10.1016/j.suc.2019.09.001

9. Garbe C, Amaral T, Peris K, et al. European consensus-based interdisciplinary guideline for melanoma. Part 2: Treatment Update 2019. Eur J Cancer. 2020;126:159-177. doi:10.1016/j. ejca.2019.11.015
10. Tchernev G, Temelkova I. The One Step Melanoma Surgery (OSMS): A New Chance for More Adequate Surgical Treatment of Melanoma Patients!? Open Access Maced J Med Sci. 2019;7(3):504-506. Published 2019 Feb 13. doi:10.3889/ oamjms.2019.147

11. Tchernev G, Temelkova I, Stavrov K. One Step Melanoma Surgery (OSMS) Without Using Ultrasonography for Preoperative Tumour Thickness Measurement? - „A Question that Sometimes Drives Me Hazy: Am I or Are the Others Crazy!“ Open Access Maced J Med Sci. 2018;6(6):1085-1090. Published 2018 Jun 6. doi:10.3889/oamjms.2018.236

12. Tchernev G, Malev V, Patterson JW, Lotti T. A novel surgical margin $(1 \mathrm{~cm})$ might be from benefit for patients with dysplastic nevi, thin melanomas, and melanoma in situ: Analysis based on clinical cases. Dermatol Ther. 2020;33(2):e13261. doi:10.1111/dth.13261

13. Chaput $L$, Laurent E, Pare A, et al. One-step surgical removal of cutaneous melanoma with surgical margins based on preoperative ultrasound measurement of the thickness of the melanoma. Eur J Dermatol. 2018;28(2):202-208. doi:10.1684/ ejd.2018.3298

14. Tchernev G, Temelkova I. Multiple Primary Cutaneous Melanomas in a Bulgarian Patient: The Possible Role of One Step Melanoma Surgery (OSMS) As the Most Adequate Treatment Approach!. Open Access Maced J Med Sci. 2018;6(11):21552160. Published 2018 Nov 21. doi:10.3889/oamjms.2018.487

15. Weyers W. „Personalized Excision“ of Malignant MelanomaNeed for a Paradigm Shift in the Beginning Era of Personalized Medicine. Am J Dermatopathol. 2019;41(12):884-896. doi:10.1097/DAD.0000000000001450

Received: 20 September 2020, Accepted: 3 October 2020 